\title{
Isolation and identification of Salmonella spp. from red foxes (Vulpes vulpes) and badgers (Meles meles) in northern Italy
}

Mario Chiari ${ }^{1 *}$, Nicola Ferrari ${ }^{2}$, Daniele Giardiello ${ }^{1}$, Paolo Lanfranchi ${ }^{2}$, Mariagrazia Zanoni ${ }^{1}$, Antonio Lavazza ${ }^{1}$ and Loris G Alborali ${ }^{1}$

\begin{abstract}
Background: Salmonella spp. have been isolated from a wide range of wild animals. Opportunistic wild carnivores such as red foxes (Vulpes vulpes) and badgers (Meles meles) may act as environmental indicators or as potential sources of salmonellosis in humans. The present study characterizes Salmonella spp. isolated from the intestinal contents of hunted or dead red foxes $(n=509)$ and badgers $(n=17)$ in northern Italy.

Findings: Thirty-one strains of Salmonella belonging to 3 Salmonella enterica subspecies were isolated. Fourteen different serovars of $S$. enterica subsp. enterica were identified, among which were serovars often associated with human illness.

Conclusions: Wild opportunistic predators can influence the probability of infection of both domestic animals and humans through active shedding of the pathogen to the environment. The epidemiological role of wild carnivores in the spread of salmonellosis needs to be further studied.
\end{abstract}

Keywords: Salmonella spp, Opportunistic carnivores, Red fox, Badger

\section{Findings}

Salmonellae are enteric bacteria capable of infecting humans and both domestic and wild animals [1]. The Center for Disease Control and Prevention and the European Food Safety Authority reports that salmonellosis is the most important foodborne infection in humans in industrialized countries [2]. Although Salmonella infections in humans are generally transmitted through food of animal origin, such as eggs, chicken, pork or beef meat [3], the role of wildlife in the maintenance of salmonellosis is of increasing interest. Salmonella spp. can be shed in faeces from healthy animals for a long period of time and can be isolated at virtually every step of the game meat chain [4]. In addition, wildlife can be involved in human salmonellosis taking part in the ecology of these bacteria and thereby contributing to the persistence of bacteria in the environment [5].

\footnotetext{
* Correspondence: mario.chiari@izsler.it

'Istituto Zooprofilattico Sperimentale della Lombardia e dell'Emilia Romagna "Bruno Ubertini", Via Bianchi 7/9, 25124 Brescia, Italy

Full list of author information is available at the end of the article
}

In the last two decades, the populations of badgers (Meles meles) and, in particular, red foxes (Vulpes vulpes) have increased and the animals have adapted to peri-urban and urban environments across Europe. Ecological factors have been attributed to the increase in fox population, in particular the abundant availability of anthropogenic food sources [6,7]. Red foxes and badgers can be considered as indicators and spreaders of zoonotic infections due to their feeding habits [8]. Indeed, they have an omnivorous diet that includes prey and plants and they also scavenge around human waste disposal sites and dustbins. Thus, they are exposed to many potential sources of Salmonella [9], considering also the fact that Salmonella spp. can survive for long periods in the soil, water, and on a variety of surfaces $[10,11]$. Presence of Salmonella spp. in the intestinal contents of red foxes and badgers may reflect true intestinal infections and potential excretion of bacteria thus suggesting the role of these species in the ecology of Salmonella spp. [12].

Plenty of literature on the prevalence of Salmonella spp. in humans, livestock and more recently, wild ungulates 
[13-15] is available, while on the contrary little is known and scarce data are available about the natural occurrence and spread of this pathogen in small carnivores.

In order to investigate the prevalence of Salmonella infections in the red fox and badger populations in northern Italy, a total of 509 hunted or found dead (including road kills) red foxes and 17 found dead (including road kills) badgers were examined. The sampling was carried out within a health monitoring program on free-ranging animals in the Lombardy Region in northern Italy from 2009 to 2010 and included both rural and peri-urban habitats. Out of the 509 foxes examined, age was reported in114, while the gender was recorded in 182 (98 adults and 16 un-weaned cubs; 100 males and 82 females).

No lesions related to salmonellosis as expected were found at necropsy neither in foxes nor in badgers as salmonellosis is often subclinical [12].

Contents of the large intestine were sampled and cultured according to the International Organization for
Standardization (ISO) 6579:2002/Amd 1:2007 method (ISO 2007) for Salmonella spp. Isolation [16]: Intestinal contents $(25 \mathrm{~g})$ were transferred to sterile sampling bags with $225 \mathrm{ml}$ of buffered peptone water and incubated at $37^{\circ} \mathrm{C}$ for $24 \mathrm{~h}$ (pre-enrichment phase). Thereafter, $0.1 \mathrm{ml}$ was inoculated on a Modified Semisolid Rappaport Vassiliadis (MSRV; Oxoid, Hampshire, UK) media and incubated for $48 \mathrm{~h}$ at $41.5^{\circ} \mathrm{C}$. Salmonella spp. suspected colonies were then plated on two selective solid media: Xylose Lysine Deoxycholate agar (XLD; bioMérieux, Bagno a Ripoli, Italy) and Brilliant Green Agar (BGA; Vacutest Kima, Arzergrande, Italy). All presumptive Salmonella spp. isolates were confirmed using biochemical tests $\left(\mathrm{BBL}^{\mathrm{Tm}}\right.$ Enterotube $^{\mathrm{Tx}}$ II, Becton Dickinson, Heidelberg, Germany). Complete serological characterization of the Salmonella strains was performed. This included rapid slide agglutination test for the detection of somatic antigens (Statens Serum Institut, Copenhagen, Denmark) and the hot tube agglutination test (Becton Dickinson, Heidelberg, Germany) for the determination of flagellar antigen. The

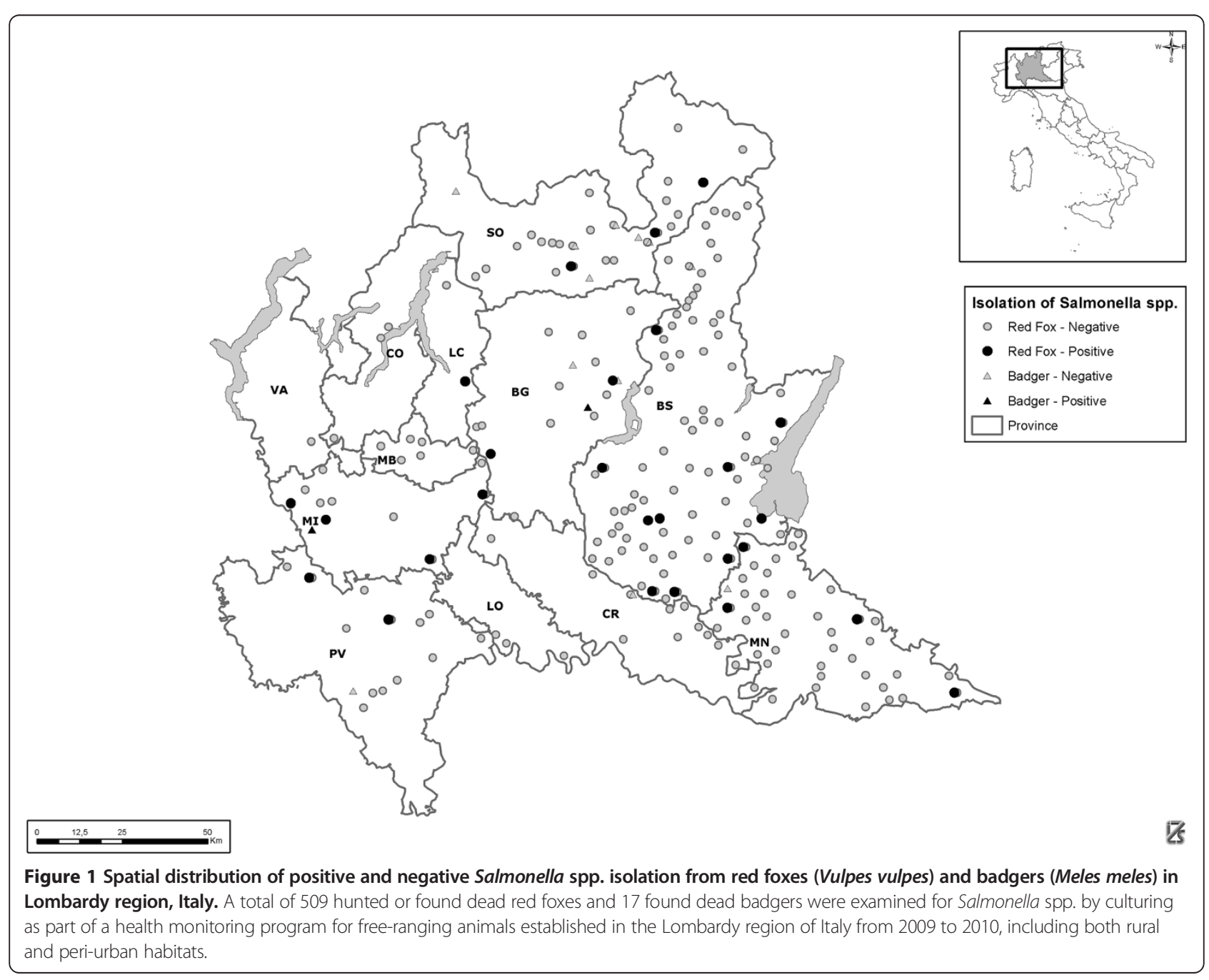


results of the antigen determination were used for the final serological characterization using the White -Kauffmann Le Minos scheme.

The prevalence of enteric Salmonella infection was calculated for each species. The exact Fisher's test was performed to evaluate the association between sex, age and the isolation of bacteria in foxes. All confidence intervals (CI) were implemented using the ClopperPearson method setting $1-\alpha=0.95$ as the confidence level.

Salmonella spp. were isolated from 29 foxes (5.70\%; 95\% CI: $3.85 \%-8.08 \%$ ) and 2 badgers (11.76\%; CI 95\% $1.46 \%-36.44 \%)$ coming from the Italian Lombardy region (Figure 1).

A prevalence of $8.00 \%$ was found in male foxes $(95 \%$ CI: $3.52 \%$ to $15.16 \%)$ while no females tested positive (0.00\%; 95\% CI: 0.00 - 4.40\%) (Table 1). Sex was significantly associated with isolation of Salmonella spp. $(P=0.01)$. Eight adult foxes were positive $(8.16 \%$; $95 \% \mathrm{CI}$ : $3.59 \%-15.45 \%)$ while no un-weaned cubs were found positive $(0.00 \%$; $95 \%$ CI: 0.00 to $20.59 \%)$ (Table 1$)$. No statistical association between age class and isolation of Salmonella spp. was found $(P=0.60)$.

Isolated Salmonella strains included 16 different serotypes in red foxes and 2 in badgers, belonging to three different subspecies of Salmonella enterica strains, i.e. S. enterica subsp. enterica (27 strains, 14 serovars), $S$. enterica subsp. diarizonae (1 strain, 1 serovars) and S. enterica subsp. houtenae (1 strain, 2 serovars) (Table 2). In particular, $S$. Typhimurium, which is often involved in cases of human salmonellosis [17], was identified in nine animals.

The prevalence of enteric salmonellosis found in foxes in the present study corresponds to observations in Norway where $6.5 \%$ of 215 red foxes were Salmonella positive [12], but only four serotypes were identified in the Norwegian study (S. Typhimurium 4,12:i:1,2, S. Hessarek, S. Kottbus and S. IIIb:61:k:1,5,(7)).

The observed prevalence of Salmonella infections in red foxes and badgers were unexpectedly low considering their omnivore feeding behaviour and the high

Table 1 Number and prevalence of Salmonella positive foxes (Vulpes vulpes) in the Lombardy region, Italy

\begin{tabular}{lllll}
\hline & & $\begin{array}{l}\text { No of } \\
\text { samples }\end{array}$ & Positive & Prevalence \\
\hline \multirow{3}{*}{ Sex } & Female & 82 & 0 & $0,00 \%(0.00 \%-4.40 \%)$ \\
& Male & 100 & 8 & $8.00 \%(3.51 \%-15.16 \%)$ \\
\cline { 2 - 4 } & Not recorded & 327 & 21 & $6.42 \%(4.02 \%-9.65 \%)$ \\
\multirow{2}{*}{ Age group } & Ydult & 98 & 8 & $8.16 \%(3.59 \%-15.45 \%)$ \\
& Young & 16 & 0 & $0.00 \%(0.00 \%-20.59 \%)$ \\
& Not recorded & 395 & 21 & $5.32 \%(3.32 \%-8.01 \%)$ \\
\hline
\end{tabular}

Table 2 Salmonella spp. isolated from red foxes (Vulpes vulpes) and badgers (Meles meles) in the Lombardy Region, Italy

\begin{tabular}{llll}
\hline S. enterica serovars & Red fox & Badger & Total \\
\hline S. enterica subsp. enterica & 25 & 2 & $27(87.09 \%)$ \\
S. Typhimurium & 8 & 1 & $9(29.03 \%)$ \\
S. Infantis & 0 & 1 & $1(3.22 \%)$ \\
S. Derby & 1 & 0 & $1(3.22 \%)$ \\
S. Enteritidis & 2 & 0 & $2(6.45 \%)$ \\
S. Mbandaka & 1 & 0 & $1(3.22 \%)$ \\
S. Enterica 4,12:i & 3 & 0 & $3(9.67 \%)$ \\
S. Napoli & 1 & 0 & $1(3.22 \%)$ \\
S. Ohio & 1 & 0 & $1(3.22 \%)$ \\
S. Anatum & 1 & 0 & $1(3.22 \%)$ \\
S. Livingston & 1 & 0 & $1(3.22 \%)$ \\
S. Hessarek & 1 & 0 & $1(3.22 \%)$ \\
S. Muenchen & 1 & 0 & $1(3.22 \%)$ \\
S. Thompson & 3 & 0 & $3(9.67 \%)$ \\
S. Veneziana & 3 & 0 & $3(9.67 \%)$ \\
S. enterica subsp. diarizonae (1 serovars) & 1 & 0 & $1(3.22 \%)$ \\
S. enterica subsp. houtenae (2 serovars) & 31 \\
Total & 1 & 2 & $1(3.22 \%)$ \\
\hline & & 0 & 31 \\
\hline
\end{tabular}

prevalence found in wild boars living in the same areas (24.82\%) [15]. Salmonella spp. have also been found in prevalences ranging from $5.5 \%$ to $24.82 \%$ in wild boars in other areas of Europe $[1,4,15,18]$. The difference in prevalence observed between foxes and wild boars may be explained by the different social behavior of these species. Indeed, the effect of animal social structure at the local scale is recognized to influence the transmission of infections between individuals [19]. Since Salmonella spp. are transmitted via a fecal-oral route, the maintenance of the infection in wild boars may be favored by large social groups that amplified the chance of contact between different individuals [20]. On the contrary foxes are characterized by small familiar groups defending their territories thus making contact between individuals less intimate.

Infection of red foxes with $S$. Typhimurium has been described as the result of ingestion of Salmonella infected, sick or dead small passerines during winter [12]. Moreover, carriage of $S$. Enteritidis by foxes near poultry farms has been related to their predatory and scavenging habits [21].

Five serovars of Salmonella subsp. enterica (i.e. S. Enteritidis, $S$. Typhimurium, $S$. Infantis, $S$. Derby, $S$. Mbandaka) represented $45.1 \%$ of the isolates. It is noteworthy that these serovars are among the 10 serovars responsible for most human cases of salmonellosis in Europe during 2010 [2]. This finding may reflect that foxes have extended their 
habitats into urban and peri-urban areas and therefore may be exposed to the same serovars as humans [6].

In conclusion, Salmonella spp. were isolated from the large intestine of $5.70 \%$ of the red foxes and $11.76 \%$ of the badgers in the Italian Lombardy region. Serovars representing $45.1 \%$ of the isolates were among the 10 serovars responsible for most cases of human salmonellosis in Europe in 2010. Consequently, wild predators, through an active shedding of the pathogen in the environment, can indirectly increase the probability of infection of both domestic animals and humans.

\section{Competing interests}

The authors declare that they have no competing interests.

\section{Authors' contributions}

$M C$ and $M Z$ carried out the majority of the bibliographic search, laboratory analyses and the preparation of the manuscript. MZ, PL and LA participated in the conception and the design of the survey. NF, PL and AL reviewed the manuscript. DG and NF performed the statistical analyses. All authors read and approved the final manuscript.

\section{Acknowledgments}

We are grateful to the hunters of Lombardy Region (northern Italy); without their cooperation these studies would not have been possible.

We are also particularly thankful to A. Tiraboschi, L. Birbes and L. Savoldini of Brescia Diagnostic Laboratory of I.Z.S.L.E.R. for their technical support. The authors wish to thank Dr. Leonardo James Vinco (IZSLER) for the editing of this manuscript.

\section{Author details}

'Istituto Zooprofilattico Sperimentale della Lombardia e dell'Emilia Romagna "Bruno Ubertini", Via Bianchi 7/9, 25124 Brescia, Italy. ${ }^{2}$ Department of Veterinary Sciences and Public Health, Università degli Studi di Milano, via Celoria 10, 20133 Milan, Italy.

Received: 5 September 2014 Accepted: 3 December 2014

Published online: 10 December 2014

\section{References}

1. Millán J, Aduriz G, Moreno B, Juste RA, Barral M: Salmonella isolates from wild birds and mammals in the Basque Country (Spain). Rev Sci Tech Off Int Epiz 2004, 23:905-911.

2. European Food Safety Authority (EFSA): The community summary report on trends and sources of zoonoses, zoonotic agents, and food-borne outbreaks in the European Union in 2010. E.F.S.A J 2012, 10:2597.

3. Pires SM, Vigre H, Makela P, Hald T: Using outbreak data for source attribution of human salmonellosis and campylobacteriosis in Europe. Foodborne Pathog Dis 2010, 7:1351-1361.

4. Paulsen P, Smulders FJM, Hilbert F: Salmonella in meat from hunted game: a central Europe perspective. Food Res Int 2012, 45:609-616.

5. Hilbert F, Smulders FJM, Chopra-Dewasthaly R, Paulsen P: Salmonella in the wildlife-human interface. Food Res Int 2012, 45:603-608.

6. Gloor S, Bontadina F, Hegglin D, Deplazes $P$, Breitenmoser U: The rise of urban fox populations in Switzerland. Mamm Biol 2001, 66:155-164.

7. Saeed IS, Kapel CMO: Population dynamics and epidemiology of Toxocara canis in Danish red foxes. J Parasitol 2006, 92:1196-1201.

8. Smith GC, Gangadharan B, Taylor Z, Laurenson MK, Bradshaw H, Hide G, Hughes JM, Dinkel A, Romig T, Craig PS: Prevalence of zoonotic important parasites in the red fox (Vulpes vulpes) in Great Britain. Vet Parasitol 2003, 118:133-142.

9. Wilson JS, Hazel SM, Williams NJ, Phiri A, French NP, Hart CA: Nontyphoidal salmonellae in United Kingdom badgers: prevalence and spatial distribution. Appl Environ Microb 2003, 69:4312-4315.

10. Thomas AD, Forbes-Faulkner JC, Speare R, Murray C: Salmonellosis in wildlife from Queensland. J Wildlife Dis 2001, 37:229-238.

11. Winfield MD, Groisman EA: Role of nonhost environments in the lifestyles of Salmonella and Escherichia coli. Appl Environ Microb 2003, 69:3687-3694.
12. Handeland K, Nesse LL, Lillehaug A, Vikøren T, Djønne B, Bergsjø B: Natural and experimental Salmonella Typhimurium infections in foxes (Vulpes vulpes). Vet Microbiol 2008, 132:129-134.

13. Wacheck S, Fredriksson-Ahomaa M, König M, Stolle A, Stephan R: Wild boars as an important reservoir for foodborne pathogens. Foodborne Pathog Dis 2010, 7:307-312.

14. Magnino S, Frasnelli M, Fabbi M, Bianchi A, Zanoni MG, Merialdi G, Pacciarini ML, Gaffuri A: The monitoring of selected zoonotic diseases of wildlife in Lombardy and Emilia-Romagna, northern Italy. In Game Meat Hygiene in Focus. Wageningen: Wageningen Academic Publishers; 2011:223-244.

15. Chiari M, Zanoni M, Tagliabue S, Lavazza A, Alborali LG: Salmonella serotypes in wild boars (Sus scrofa) hunted in northern Italy. Acta Vet scand 2013, 55:42-45.

16. International Organization for Standardization (ISO): Microbiology of Food and Animal Feeding Stuff-Horizontal Method for the Detection of Salmonella. ISO 6579. Geneva: International Organization for Standardization; 2002.

17. Cruchaga S, Echeita A, Aladueña A, García-Peña J, Frias N, Usera MA: Antimicrobial resistance in salmonellae from humans, food and animals in Spain in 1998. J Antimicrob Chemother 2001, 47:315-321.

18. Sannö A, Aspán A, Hestvik G, Jacobson M: Presence of Salmonella spp., Yersinia enterocolitica, Yersinia pseudotuberculosis and Escherichia coli 0157: H7 in wild boars. Epidemiol Infect 2014, 1-6.

19. Ferrari N, Rosà R, Lanfranchi P, Ruckstuhl KE: Effect of sexual segregation on host-parasite interaction: Model simulation for abomasal parasite dynamics in alpine ibex (Capra ibex). Int J Parasitol 2010, 40:1285-1293.

20. Kaminski G, Brandt S, Baubet E, Badoin C: Life-history patterns in female wild boars (Sus scrofa): mother-daughter postweaning associations. Can J Zoo 2005, 83:474-480.

21. Graziani C, Busani L, Dionisi AM, Caprioli A, Ivarsson S, Hedenström I, Luzzi I: Virulotyping of Salmonella enterica serovar Napoli strains isolated in Italy from human and nonhuman sources. Foodborne Pathog Dis 2011, 8:997-1003.

\section{doi:10.1186/s13028-014-0086-7}

Cite this article as: Chiari et al:: Isolation and identification of Salmonella spp. from red foxes (Vulpes vulpes) and badgers (Meles meles) in northern Italy. Acta Veterinaria Scandinavica 2014 56:86.

\section{Submit your next manuscript to BioMed Central and take full advantage of:}

- Convenient online submission

- Thorough peer review

- No space constraints or color figure charges

- Immediate publication on acceptance

- Inclusion in PubMed, CAS, Scopus and Google Scholar

- Research which is freely available for redistribution 